\title{
Ön çapraz bağ yaralanmasında cerrahi zamanlama
}

\section{Timing of the anterior cruciate ligament tear surgery}

\author{
Yusuf İyetin¹, Burak Özturan², Oğuz Şükrü Poyanlı² \\ ${ }^{1}$ Özel Pendik Bölge Hastanesi, Ortopedi ve Travmatoloji Kliniği, İstanbul, Türkiye \\ ${ }^{2}$ İstanbul Medeniyet Üniversitesi, Göztepe Eğitim Araştırma Hastanesi, Ortopedi ve Travmatoloji Anabilim Dalı/Kliniği, İstanbul, Türkiye
}

Ön çapraz bağ (ÖÇB) rüptürü en yaygın görülen bağ yaralanmalarından biridir. Bu yaralanma ile ilgili günümüzde çok fazla sayıda cerrahi tedavi yapılmaktadır. ÖÇB rüptürü için en yaygın tedavi rekonstrüksiyon olsa da, literatürde cerrahinin optimal zamanlaması konusunda tartışmalar devam etmektedir. Önceki yazarlar, erken rekonstrüksiyonun erken dönemde işe veya spora dönüşü kolaylaştırabileceğini, ancak artrofibrozis gibi ameliyat sonrası komplikasyon insidansını artırabileceğini öne sürmüşlerdir. ÖÇB rüptürü sonrası cerrahi tedavi yapılmazsa ilerleyen dönemlerde dizde özellikle iç menisküs yırtığı ve kıkırdak hasarı gelişme olasılığı yüksektir. Cerrahi tedavi sonrası gelişebilecek olan eklem hareket açıklığında azalma (artrofibrozis) korkulan bir komplikasyondur. Erken cerrahi tedavinin artrofibrozis gelişme riskini artırdığına dair yayımlanmış eski yayınlar mevcuttur. Son zamanlarda erken veya geç cerrahi tedavi arasında artrofibrozis gelişme riski açısından anlamlı fark bulunmadığına dair yayınlar da mevcuttur. Bu çalışma, ÖÇB rekonstrüksiyonunun rüptürden sonra akut olarak gerçekleştirilip gerçekleştirilmeyeceğini belirlemek için literatürü sistematik olarak gözden geçirmiştir.

Anahtar sözcükler: ön çapraz bağ; artrofibrozis; rekonstrüksiyon; zamanlama

\begin{abstract}
Anterior cruciate ligament ( $A C L$ ) rupture is one of the most common ligament injuries. There are a lot of surgical treatments related to ACL injury today. Although the most common treatment for ACL rupture is reconstruction, the discussions about optimal timing of surgery are ongoing. Previous authors submitted that early reconstruction can facilitate the return to work or sports in the early period, however, it may suggest that it may increase the incidence of postoperative complications such as arthrofibrosis. If the ACL rupture would not be treated (reconstructed) surgically, there is a high probability of developing internal meniscus tears and cartilage damage in the knee. Decreasing in range of motion that may develop after surgical treatment (arthrofibrosis) is a feared complication. Although there are some publications which indicated increased risk of arthrofibrosis on early surgical treatment, recently published paper works stating there is no significant difference between early or late surgical treatment as well. This study looks over the literature systematically to determine whether ACL reconstruction will be carried out acutely after rupture.
\end{abstract}

Key words: anterior cruciate ligament; arthrofibrosis; reconstruction; timing

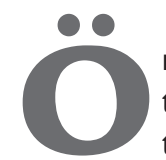

n çapraz bağ (ÖÇB) yaralanmasının cerrahi tedavisinin optimal zamanlaması konusunda tartışmalar devam etmektedir. Erken cerrahi tedavide en çok korkulan komplikasyon hastalarda artrofibrozis gelişme riskidir. ${ }^{[1]}$ Artrofibrozisin neden olduğu ameliyat sonrası sertliğin (hareket kaybı) diz fonksiyonu üzerinde olumsuz bir etkisi vardır. ${ }^{[2]}$ Ameliyat zamanlamasının ÖÇB rekonstrüksiyon cerrahisi sonrası sertlik riski üzerinde etkisi olduğuna dair yaygın bir inanç vardır. ${ }^{[2-4]}$ Cerrahinin gecikmesi ise ilerleyen dönemlerde hastalarda menisküs yaralanmalarına ve kıkırdak hasarına yol açabilmektedir. ${ }^{[5]}$ Hasta açısından bakıldığında, üst düzey sporcular sıklıkla erken spora dönebilmek için mümkün olan en kısa zamanda ameliyat istemektedir. Fiziksel olarak zorlayıcı faaliyetlerle ilgilenmeyen hastalar ise, kişisel veya toplumsal zorunluluklar nedeniyle ameliyatı geciktirebilirler. Her iki durumda da, bu çalışmada tartışılacak olan olumsuz komplikasyonlar hasta sonuçlarını olumsuz etkileyebilir. Fizyoterapistler de dâhil olmak üzere sağlık hizmeti sağlayıcıları, hastaları uygun şekilde eğitmek için erken ve gecikmiş cerrahi müdahale riskleri konusunda bilgi sahibi olmalıdır. ${ }^{[6]}$

- İletişim adresi: Dr. Yusuf İyetin, Doğu Nevbahar Sok. No:1, 34890, Özel Pendik Bölge Hastanesi, Ortopedi ve Travmatoloji Kliniği, Pendik, İstanbul Tel: 0530 - 5054139 e-posta: y.iyetin@gmail.com

- Gelis tarihi: 14 Nisan $2020 \quad$ Kabul tarihi: 30 Nisan 2020 
Shelbourne ve ark., yayımladıkları makalelerinde geriye dönük olarak 169 akut ÖÇB rekonstrüksiyonunu incelemiş ve cerrahi zamanlamanın ve hızlandırılmış rehabilitasyonun hasta sonuçları üzerindeki etkisini değerlendirmişlerdir. Yaralanmanın ilk haftası içinde rekonstrüksiyon yapılan hastalarda, yaralanmadan üç hafta geçtikten sonra cerrahi geçirenlere kıyasla artrofibrosizde belirgin bir artış görülmüştür. ${ }^{[1]} \mathrm{O}$ yıllarda yapılan bir kaç çalışma bu öneriyi desteklemiştir. ${ }^{[7,8]}$ ilginç bir şekilde, yaralanmadan 8 ila 21 gün sonra rekonstrüksiyon yapılmış ve hızlandırılmış rehabilitasyon programına alınan hastalarda artrofibrozis görülme sıklığı, konvansiyonel rehabilitasyon programına alınmış hastalara göre daha düşük bulunmuştur. Bununla birlikte, bu çalışma yapıldı̆̆ından beri yaklaşık 25 yıl geçmiştir ve ÖÇB rekonstrüksiyonu ile ilişkili akut yönetim ve cerrahi teknikte birçok gelişme olmuştur. Bu nedenle sonuçlar dikkatle yorumlanmalıdır.

Shelbourne ve Patel, ameliyattan önce dikkate alınması gereken ameliyat dönemi faktörlerini gözden geçirmişlerdir. Yazarlar, rekonstrüksiyon zamanlamasını belirlemek için zihinsel hazırlık, zamanlama, ilişkili diz eklem patolojisi (menisküs yırtığı, kıkırdak hasarı) ve ameliyat öncesi diz durumunun (yani şişlik, minimum güç ve tam hareket aralığı) dikkatle değerlendirilmesi gerektiği sonucuna varmışlardır. ${ }^{9]}$

Almekinders ve ark., kemik-tendon-kemik otogrefti kullanılarak ÖÇB rekonstrüksiyonu uygulanan 70 yetişkini incelemişlerdir. Yaralanma sonrası bir aydan daha kısa bir sürede rekonstrüksiyon yapılan hastalarda erken diz hareket açıklığında kısıtlılık görülmüş; ancak bir yıl sonra erken veya geç cerrahi geçiren hastalar arasında hareket farkı olmadığını belirtmişlerdir. ${ }^{[10]}$

Passler ve ark., 283 hastada cerrahi girişim zamanlaması ile ilişkili komplikasyonları değerlendirmiştir. Yaralanmadan sonraki ilk bir hafta içinde ameliyat olan bireylerin yaklaşık \%18'inde, en az dört hafta bekleyen hastaların ise sadece \%6'sında artrofibrozis geliştiğini görmüşlerdir. ${ }^{[1]]}$

Bottoni ve ark., erken rekonstrüksiyon yapılan hastalar ile en az altı hafta bekleyen hastalar arasında diz hareket açıkığı arasında anlamlı bir fark bulamamışlardır. ${ }^{[12]}$

Mayr ve ark., zamanlama ve ameliyat öncesi diz durumunun ÖÇB rekonstrüksiyonu sonuçları üzerine etkisini inceledikleri bir çalışmada; ameliyattan önce dizin şişlik, effüzyon, ısı artışı, eklem hareket açıklığı ve ek yaralanmaların durumunu değerlendirmişlerdir. Yazarlar, yaralanmanın ilk dört haftasında yapılan rekonstrüksiyon ile artrofibrozis gelişimi arasında bir ilişki olduğunu bildirmişlerdir. Bununla birlikte,

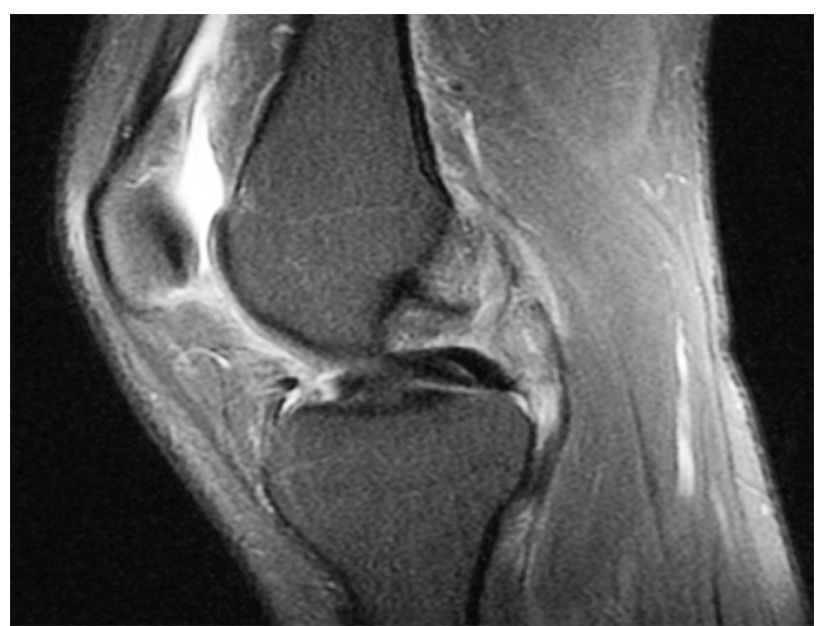

Şekil 1. Kronik ÖÇB rüptürü sonrası medial menisküs kova sapı yırtığının sagittal kesitte MR görüntüsü.

yazarlar ayrıca ameliyat öncesi dizde bulunan hasar ile artrofibrozis arasında güçlü bir ilişki bulmuşlardır. İlginç bir şekilde, dört hafta sonra rehabilite olmamış bir diz ile ameliyat geçirenler, daha erken rekonstrüksiyon yapılanlarla aynı artrofibrozis gelişme olasılığına sahip bulunmuştur. Ameliyat öncesi diz ekstansiyonu ve fleksiyonu kısıtlı olan hastalarda ise ameliyat sonrası artrofibrozis riski daha fazla görülmüştür. Bu çalışmanın sonuçları, ameliyattan önce dizin durumunun, rekonstrüksiyonun optimal zamanlamasını belirlemede yaralanma ile ameliyat arasında geçen süreden daha önemli bir faktör olabileceğini göstermektedir. ${ }^{[13]}$

Son zamanlarda, erken cerrahinin ameliyat sonrası eklem hareket açıklığını önemli ölçüde etkilemediğini öne süren birkaç randomize kontrollü çalışma yayımlanmıştır. ${ }^{[12,14-17]}$ Gecikmiş rekonstrüksiyon iyi sonuçlar gösterse de erken ameliyatın istenmesi, spor aktivitesine ve fiziksel çalışmaya daha erken geri dönmeyi sağlar. Ameliyatın altı hafta veya daha uzun bir süre ertelenmesi, rezeksiyon gerektiren menisküs yaralanması riskinin artmasıyla ilişkilendirilmesi daha da önemli bir gerekçe olabilir (Şekil 1). ${ }^{[5,14,15,18]}$

Barenius ve ark., patellar tendon ve hamstring greftleri kullanarak ameliyat ettikleri 153 ÖÇB rekonstrüksiyon hastasının sekiz yıllık takip sonuçlarını incelemişlerdir. Erken rekonstrüksiyon yapılan hastalarda, geç rekonstrüksiyon yapılan hastalara göre fiziksel ve sosyal işlevsellikte daha iyi sonuçlar almışlar ve artrofibrosizle ilgili anlamlı fark bulamamışlardır. Çalışmalarının sonucunda menisküs hasarının diz fonksiyonunu olumsuz etkilediği ve erken rekonstrüktif cerrahinin yararlı olduğunu belirtmişlerdir. ${ }^{[14]}$ 
Bottoni ve ark., otolog hamstring greftlerle ameliyat ettikleri 69 hastayı incelemeye aldıkları çalışmada; 34 hastaya ilk üç hafta içinde akut cerrahi, 35 hastaya ise ameliyattan ortalama altı hafta sonra gecikmiş cerrahi yapılmıştır. Ortalama bir yıllık takip sonucunda iki grup arasında artrofibrozis açısından anlamlı bir fark bulunamamıştır. Otogreft hamstringleri kullanılarak yaralanmadan kısa süre sonra yapılan ÖÇB rekonstrüksiyonlarından sonra mükemmel klinik sonuçlar elde edilebildiği sonucuna varmışlardır. ${ }^{[12]}$ Her ne kadar yazarlar tüm rekonstrüksiyonların akut olarak yapılması gerektiğini savunmasalar da, erken ÖÇB rekonstrüksiyonlarının ekstansiyon ve erken hareket aralığını vurgulayan bir rehabilitasyon protokolü kullanıldığı sürece hareket kaybına veya yetersiz klinik sonuçlara yol açmadığını bulmuşlardır. ${ }^{[12]}$

Frobell ve ark., akut ÖÇB yaralanması olan 121 genç, aktif yetişkini içeren randomize, kontrollü bir çalışmada; 59 hastaya erken ÖÇB rekonstrüksiyonu ve rehabilitasyon uygulamışlardır. Geri kalan hastalar rehabilitasyona alınmış ve bu hastaların 23'üne geç rekonstrüksiyon yapılmıştır. Erken ve geç rekonstrüksiyon yapılan hastalar arasında eklem hareket açıklı̆̆ı açısından anlamlı bir fark bulunamamıştır. ${ }^{[15]}$

Meighan ve ark., akut ÖÇB yaralanması olan 31 hastayı, erken (iki hafta içinde) veya gecikmiş (8-12 hafta) rekonstrüksiyon olacak şekilde randomize etmişler. Ameliyattan sonraki ilk 12 hafta içinde yapılan tüm ölçümler için fleksiyon aralığı erken opere edilen hastalarda azalmış ve bu fark iki hafta için anlamlı bulunmuştur. Herhangi bir aşamada iki grup arasında diz ekstansiyon kaybı açısından anlamlı bir fark görülmemiştir. Son takipte (52 hafta) her iki gruptaki ortalama eklem hareket açıklığı aynı bulunmuştur. Her grupta bir hastada klinik olarak anlamlı artrofibrozis geliştiği görülmüştür. ${ }^{[16]}$

Raviraj ve ark., erken rekonstrüksiyon (yaralanmadan sonraki ilk iki hafta) yaptıkları 51 hastayı ve geç rekonstrüksiyon yaptıkları (yaralanmadan en az dört hafta sonra) 48 hastanın ortalama 32 ay takip sonuçlarını değerlendirmişler ve iki grup arasında artrofibrozis açısından anlamlı bir fark bulamamışlardır. ${ }^{[17]}$

Smith ve ark., yaptıkları meta-analiz çalışmalarına 370 ÖÇB rekonstrüksiyon hastasını içeren altı makale dâhil etmişlerdir. Erken ÖÇB rekonstrüksiyonları, yaralanma sonrası ortalama üç hafta içinde yapılanlar olarak kabul edilmiş; gecikmiş ÖÇB rekonstrüksiyonları ise yaralanmadan en az altı hafta sonra yapılanlar olarak kabul edilmiştir. Erken yapılan hastalarda gecikmiş ÖÇB rekonstrüksiyonuna göre klinik sonuçlarda anlamlı fark bulamamışlardır. ${ }^{[19]}$
Son zamanlarda yapılan çalışmalarda iyi bir rehabilitasyon ile erken ön çapraz bağ rekonstrüksiyonu yapılan hastaların artrofibrozis riskinin anlamlı derecede yüksek olmadığı görülmüştür. Ameliyat öncesi diz içi effüzyon, hareket kısıtlılığ, kas kuvvetinde önemli derecede azalma, dizde bulunan ek yaralanma (menisküs yırtığı, kıkırdak hasarı) ameliyat sonrası rehabilitasyonu önemli derecede etkilemektedir. Ayrıca hastanın sosyal durumu da (çalışma şartları, eğitim durumu, yaşı) ameliyat sonrası rehabilitasyonu önemli derecede etkilemektedir. Ameliyat zamanlaması yapılırken tüm bu faktörler dikkatlice değerlendirilmelidir.

Ameliyatın geciktirilmesi ileride oluşabilecek diz içi menisküs hasarı ve kıkırdak hasarına zemin hazırlayabilmektedir (Şekil 2).

Yoo ve ark., yaptıkları çalışmalarında ön çapraz bağ rekonstrüksiyonu geciken hastalarda iç menisküs yırtığı riskinin arttığına dair kanıtlar bulmuşlardır. ${ }^{[5]}$

Kennedy ve ark., yaptıkları çalışmalarında ilk yaralanmadan bir yıl sonra opere edilen sporcularda medial menisküs yaralanma sıklığını oldukça yüksek bulmuşlar. Lateral menisküs yırtığı sıklığında ise anlamlı bir fark bulamamışlardır. Ayrıca yaralanmadan altı ay sonra diz içi dejeneratif değişiklerde artış görmüşlerdir. ${ }^{20]}$

Ahlen ve ark., ÖÇB yaralanması sonrası ilk beş ay içinde ameliyat edilen hastaların sonuçlarının, yaralanma sonrasında 24 ay bekleyen hastalara göre daha iyi olduğunu bildirmişlerdir. ${ }^{[21]}$

Granan ve ark., Norveç'teki ÖÇB rekonstrüksiyon olguları hakkında ileriye dönük olarak bilgi toplayan büyük bir kohort çalışması yapmışlardır. Yazarlar, cerrahi müdahalenin zamanlaması ile ek patoloji geliştirme riski arasındaki ilişkiyi belirlemek için primer ÖÇB rekonstrüksiyonu uygulanan 3699 hastayı analiz etmişlerdir. Yazarlar çocuklarda artiküler kıkırdak bozulması veya menisküs patolojisi arasında bir iliş̧i bulamamışlardır (16 yaş ve altı). Bununla birlikte, genç erişkinlerde (17-40 yaş) ve daha büyük erişkinlerde (41 yaş ve üstü), ilk yaralanmadan cerrahiye geçen her ay için, eklem kıkırdağı lezyonu gelişme riskinin yaklaşık \%1 arttığını bildirmişlerdir. ${ }^{[22]}$

Anstey ve ark., ilk altı ayda ÖÇB rekonstrüksiyonu yapılan hastalarda \%4,1 iç menisküs yırtığı, altı aydan sonra opere edilen hastalarda da $\% 16,7$ iç menisküs yırtığı tespit etmişlerdir. ${ }^{[23]}$

Akut ve geç cerrahi arasındaki avantaj ve dezavantajlar Tablo 1'de gösterilmiştir. 

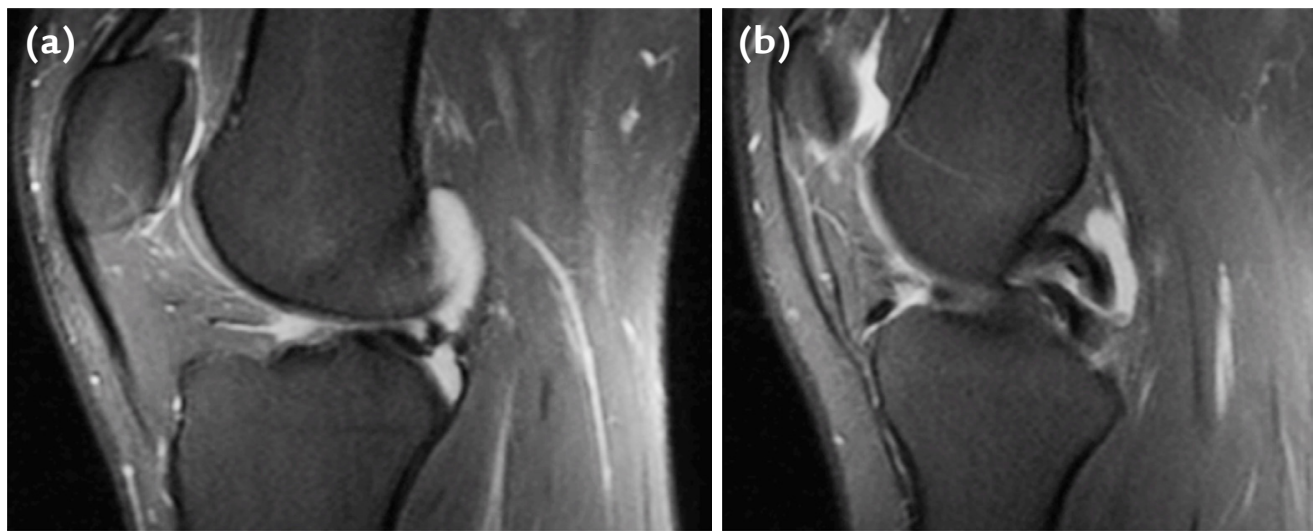

Şekil 2. a-d. On dokuz yaşındaki hastada MR görüntüsü; kronik ÖÇB yaralanması (a), kova sapı medial menisküs yırtığı (b), lateral femoral kondil kıkırdak hasarı (c) ve retropatellar kıkırdak hasarı (d).
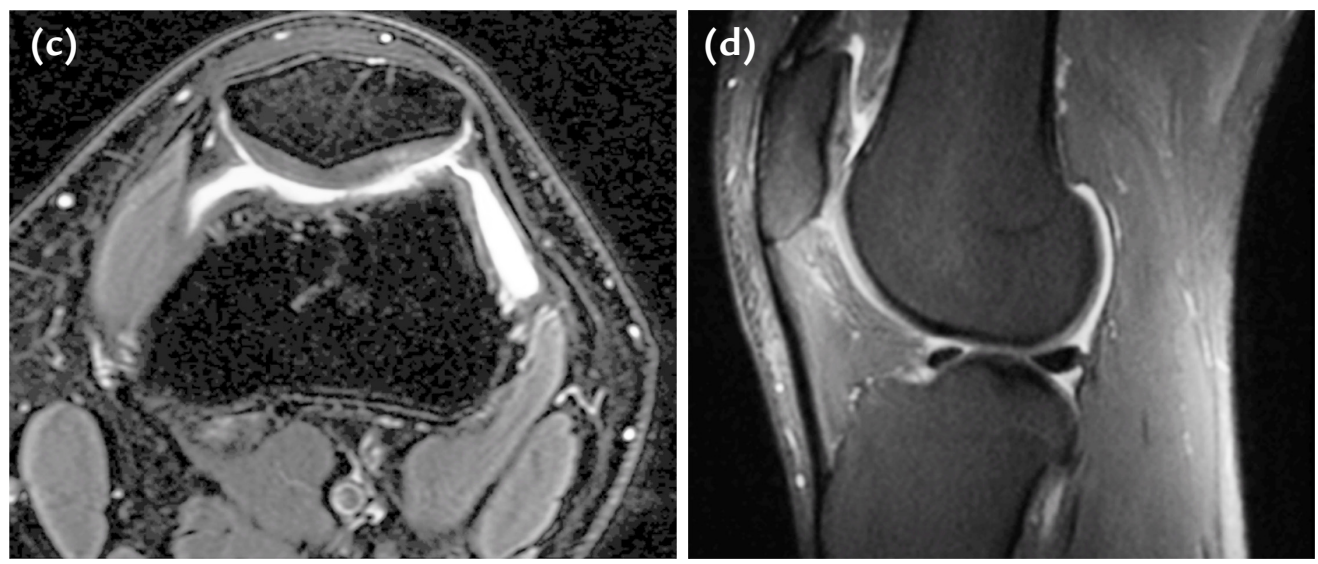

Tablo 1. Akut ve geç cerrahi arasındaki avantaj ve dezavantajlar

\begin{tabular}{lll}
\hline & Avantaj & Dezavantaj \\
\hline Akut rekonstrüksiyon & $\begin{array}{l}\text { Erken işe dönüş } \\
\text { Menisküs ve kıkırdak tamiri başarılı } \\
\text { Kuadriseps güçlü }\end{array}$ & Artrofibrozis riski \\
& $\begin{array}{l}\text { Artrofibrozis riski az } \\
\text { Geç rekonstrüksiyon }\end{array}$ & $\begin{array}{l}\text { Ek patoloji tamir sorunu } \\
\text { Mental hazırlık }\end{array}$
\end{tabular}

\section{TARTIŞMA}

ÖÇB rekonstrüksiyonunun optimal zamanlaması, hasta sonuçlarını önemli ölçüde etkileyen önemli bir klinik karardır. ${ }^{6]}$ Literatürde fikir birliği olmamasına rağmen, ameliyat zamanlaması ile ilgili bazı eğilimler vardır. Eski çalışmalar artrofibrozisi önlemek için ÖÇB rekonstrüksiyonunun yaralanmadan en az üç hafta sonra yapılmasını önermektedirler..$^{[1,9-11]}$ Artrofibrozisten korunmak için zamanlama kadar önemli bir durum da ameliyat öncesi dizde bulunan hasardır. Ameliyat öncesi dizde bulunan hasarın (dizde effüzyon, eklem hareket açıklığında ciddi kısıtlııı, ağrının fazla olması) derecesi artrofibrozis riskini etkilemektedir. ${ }^{[13]}$ Ameliyat öncesi kuadriseps tendon gücünün $\% 80$ olana kadar beklenmesini öneren yazarlar da vardır. ${ }^{[24]}$ Kuvveti düşük kuadriseps tendonu ile operasyona alınan hastalarda iki yıl sonrada bacak kuvvetinde önemli derecede kuvvet kaybı tespit edilmiştir. ${ }^{[24]}$ Daha güncel yayınlarda erken veya geç yapılan cerrahi arasında artrofibrozis gelişme riski açısından anlamlı fark bulunamamıştır. ${ }^{[2,14-17]}$ İyileştirilmiş cerrahi teknikler geliştikçe ameliyat sonrası rehabilitasyon da önemli ölçüde değişmiştir. ${ }^{[6]}$ Güncel cerrahi teknikler ve yapılan modern fizik tedavi yöntemleri sonrasında cerrahi tedavinin daha erken yapılabileceği düşünülmektedir.

Cerrahi tedavi geciktikçe dizde iç menisküs yırtığı ve kıkırdak hasar riski önemli derecede artmaktadır. ${ }^{[5,20-23]}$ 


\section{SONUÇ}

ÖÇB rekonstrüksiyonunun ne zaman yapılacağı kararı muhtemelen çok faktörlüdür. Ameliyat öncesi dizin durumu, aile, okul veya iş yükümlülüklerinin durumu ve zihinsel hazırlık gibi faktörleri içerebilir. ÖÇB rüptürünün hem erken hem de gecikmiş cerrahi rekonstrüksiyonunda, klinik sonuçları olumsuz etkileyebilecek önemli potansiyel komplikasyonlar vardır. Hem fizyoterapist hem de cerrah dahil olmak üzere sağlık uzmanları ÖÇB rekonstrüksiyonunun optimal zamanlaması konusunda hastalarına gerekli bilgilendirmeyi yaptığında ve sonucunda ortak alınan bir kararla ameliyatın zamanı belirlendiğinde, bu komplikasyonlar önemli ölçüde azalabilir.

\section{KAYNAKLAR}

1. Shelbourne KD, Wilcken JH, Mollabashy A, DeCarlo M. Arthrofibrosis in acute anterior cruciate ligament reconstruction. The effect of timing of reconstruction and rehabilitation. Am J Sports Med 1991;19(4):332-6. Crossref

2. Kwok CS, Harrison T, Servant C. The Optimal Timing for Anterior Cruciate Ligament Reconstruction With Respect to the Risk of Postoperative Stiffness. Arthroscopy 2013;29(3):556-65. Crossref

3. Beynnon BD, Johnson RJ, Abate JA, Fleming BC, Nichols CE. Treatment of anterior cruciate ligament injuries: Part I. Am J Sports Med 2005;33(10):1579-602. Crossref

4. Magit D, Wolff A, Sutton K, Medvecky MJ. Arthrofibrosis of the knee. J Am Acad Orthop Surg 2007;15(11):682-94. Crossref

5. Yoo JC, MD, Ahn JH, Lee SH, Yoon YC. Increasing Incidence of Medial Meniscal Tears in Nonoperatively Treated Anterior Cruciate Ligament Insufficiency Patients Documented by Serial Magnetic Resonance Imaging Studies. Am J Sports Med 2009;37(8):1478-83. Crossref

6. Evans S, Shaginaw J, Bartolozzi A. ACL Reconstruction - it's all about timing. The Int J Sports Phys Ther 2014;9(2):268-73. https://www.ncbi.nlm.nih.gov/pmc/articles/PMC4004131/

7. Harner CD, Irrgang JJ, Paul J, Dearwater S, Fu FH. Loss of motion after anterior cruciate ligament reconstruction. Am J Sports Med 1992;20(5):499-506. Crossref

8. Wasilewski SA, Covall DJ, Cohen S. Effect of surgical timing on recovery and associated injuries after anterior cruciate ligament reconstruction. Am J Sports Med 1993;21(3):338-42. Crossref

9. Shelbourne KD, Patel DV. Timing of surgery in anterior cruciate ligament-injured knees. Knee Surg Sports Traumatol Arthrosc 1995;3(3):148-56. Crossref

10. Almekinders LC, Moore T, Freedman D, Taft TN. Postoperative problems following anterior cruciate ligament reconstruction. Knee Surg Sports Traumatol Arthrosc 1995;3(2):78-82. Crossref

11. Passler JM, Schippinger G, Schweighofer F, Fellinger M, Seibert FJ. Complications in 283 cruciate ligament replacement operations with free patellar tendon transplantation. Modification by surgical technique and surgery timing. Unfallchirurgie 1995;21(5):240-6. Crossref
12. Bottoni CR, Liddell TR, Trainor TJ, Freccero DM, Lindell KK. Postoperative range of motion following anterior cruciate ligament reconstruction using autograft hamstrings. A Prospective, Randomized Clinical Trial of Early Versus Delayed Reconstructions. Am J Sports Med 2008;36(4):65662. Crossref

13. Mayr HO, Weig TG, Plitz W. Arthrofibrosis following ACL reconstruction --reasons and outcomes. Arch Orthop Trauma Surg 2004;124(8):518-22. Crossref

14. Barenius B, Nordlander M, Ponzer S, Tidermark J, Eriksson K. Quality of life and clinical outcome after anterior cruciate ligament reconstruction using patellar tendon graft or quadrupled semitendinosus graft. Am J Sports Med 2010;38(8):1533-41. Crossref

15. Frobell RB, Roos EM, Roos HP, Ranstam J, Lohmander LS. A randomized trial of treatment for acute anterior cruciate ligament tears. N Engl J Med 2010;363(4):33142. Crossref

16. Meighan AAS, Keating JF, Will E. Outcome after reconstruction of the anterior cruciate ligament in athletic patient sea comparison of early versus delayed surgery. J Bone Joint Surg Br 2003;85(4):521-4. Crossref

17. Raviraj A, Anand A, Kodikal G, Chandrashekar M, Pai S. A comparison of early and delayed arthroscopically-assisted reconstruction of the anterior cruciate ligament using hamstring autograft. J Bone Joint Surg Br 2010;92(4):521-6. Crossref

18. Chhadia AM, Inacio MC, Maletis GB, Csintalan RP, Davis $\mathrm{BR}$, Funahashi TT. Are meniscus and cartilage injuries related to time to anterior cruciate ligament reconstruction? Am J Sports Med 2011;39(9):1894-9. Crossref

19. Smith TO, Davies L, Hing CB. Early versus delayed surgery for anterior cruciate ligament reconstruction: a systematic review and meta-analysis. Knee Surg Sports Traumatol Arthrosc 2010;18(3):304-11. Crossref

20. Kennedy J, Jackson MP, O'Kelly P, Moran R. Timing of reconstruction of the anterior cruciate ligament in athletes and the incidence of secondary pathology within the knee. J Bone Joint Surg Br 2010;92(3):362-6. Crossref

21. Ahlen M, Liden M. A comparison of the clinical outcome after anterior cruciate ligament reconstruction using a hamstring tendon autograft with special emphasis on the timing of the reconstruction. Knee Surg Sports Traumatol Arthrosc 2011;19(3):488-94. Crossref

22. Granan LP, Bahr R, Lie SA, Engebretsen L. Timing of anterior cruciate ligament reconstructive surgery and risk of cartilage lesions and meniscal tears. Am J Sports Med 2009;37(5):95561. Crossref

23. Anstey DE, Heyworth BE, Price MD, Gill TJ. Effect of timing of $A C L$ reconstruction in surgery and development of meniscal and chondral lesions. Phys Sportsmed 2012;40(1):36-40. Crossref

24. Eitzen I, Holm I, Risberg MA. Preoperative quadriceps strength is a significant predictor of knee function two years after anterior cruciate ligament reconstruction. Br J Sports Med 2009;43(5):371-6. Crossref 